\title{
CARACTERIZAÇÃO MORFOLÓGICA DE MICROENXERTIA EM MACIEIRA ${ }^{1}$
}

\author{
JÚLIO CÉSAR DE OLIVEIRA NUNES², MONITA FIORI DE ABREU³ ${ }^{3}$ ADRIANA CIBELE DE MESQUITA DANTAS ${ }^{4}$, \\ ADILSON JOSÉ PEREIRA ${ }^{5}$, ENIO LUIZ PEDROTTI ${ }^{6}$
}

\begin{abstract}
RESUMO - A microenxertia pode ser uma alternativa eficiente para a propagação de plantas de elevada qualidade genética e fitossanitária, em um reduzido período de tempo e sob condições controladas. O objetivo deste trabalho foi realizar a microenxertia em plantas micropropagadas sob efeito dos fitorreguladores AIB e BAP, nas combinações de Gala/M9 e Gala/Marubakaido. Para a combinação Gala/Marubakaido, foi constatado o menor número de folhas para o tratamento com 2,2 $\mu \mathrm{M}$ de AIB, e para os demais tratamentos não houve diferença significativa. Após a aclimatização, a sobrevivência dos microenxertos foi de 92,5\% para combinação Gala/Marubakaido e 88,5\% para Gala/M9. O trabalho foi desenvolvido no Laboratório de Bioquímica e Morfogênese Vegetal (CCA - UFSC).
\end{abstract}

Termos para indexação: enxertia in vitro, Malus spp., fitorreguladores.

\section{MORPHOLOGIC CHARACTERIZATION IN APPLE MICROGRAFTS}

\begin{abstract}
The micrografting technique can provide an efficient production of high quality genetic plants, in a short time period and under controlled and aseptic conditions. The aim of this work was the study of micrografting technique by using in vitro plants and verifying the influence of application of growth regulators IBA and BAP, in Gala/M9 and Gala/Marubakaido scion-rootstock combinations. The combination Gala/Marubakaido had the lowest number of leaves when treated with $2,2 \mu \mathrm{M}$ of IBA. However none of the other treatments had significant statistical differences. After acclimatization, the survivor rates from the micrografts were $92,5 \%$ to Gala/Marubakaido combination and 88,5\% to Gala/M9. This study was developed in the Biochemistry and Vegetal Morphogeneses Laboratory (CCA - UFSC).
\end{abstract}

Terms of index: in vitro grafting, Malus spp., growth regulators.

\section{INTRODUÇÃO}

No Brasil, os viveiros e os pomares de macieira estão localizados em regiões nas quais os fatores climáticos e edáficos são notadamente diferenciados daqueles que ocorrem nas demais regiões de cultivo no mundo. Como conseqüência, é freqüente a associação destes portaenxertos com problemas fisiológicos e/ou fitossanitários (Bonetti et al., 2001). A produtividade do pomar depende do genótipo e da qualidade da muda. Nesse contexto, a micropropagação vem sendo utilizada para produção de plantas-matrizes básicas, pois possibilita altas taxas de multiplicação a partir de um meristema. Além disso, é possível produzir em um curto período de tempo e com espaço físico reduzido (Lambardi et al., 1997).

A microenxertia foi utilizada como técnica de micropropagação e eliminação de viroses inicialmente por Murashige et al. (1972) e melhorada por Navarro et al. (1975), tornando-se eficiente na obtenção de plantas cítricas livres de vírus, mas recebeu algumas adaptações. Esta técnica tem sido aplicada na macieira (Alskief \& Villemur, 1977), damasqueiro (Martinez et al., 1979), videira (Tannè et al., 1993), pereira e marmeleiro (Zecca et al., 1995), trazendo várias vantagens, tais como a obtenção de plantas livres de patógenos, detecção precoce de incompatibilidade entre espécies, estudo das relações correlativas entre porta-enxertos e copas, estudo de combinações específicas entre genótipos adaptados a condições edáficas para incrementar a produtividade da planta (Mosella-Chancel et al., 1980a; Richardson et al., 1996; Prakash et al., 1999; Estrada-Luna et al., 2002).

Em macieira, principalmente em cultivares com dificuldade de enraizamento in vitro, a microenxertia pode ser também uma técnica de produção de material livre das viroses (Zhu et al., 1999). Para alcançar este objetivo, é necessário seguir os seguintes passos: preparação do porta-enxerto; preparação do enxerto; enxertia; desenvolvimento in vitro das plantas enxertadas, e transferência das plantas para o solo (Navarro, 1988). Entretanto, o sucesso na utilização da microenxertia para obtenção de material propagativo livre de doenças depende de outros fatores, dentre os quais o pré-tratamento com reguladores de crescimento, com o objetivo de acelerar a cicatrização dos tecidos no ponto de enxertia, resultando em maior sobrevivência dos mesmos (Jeffree \& Yeoman, 1983; Harbage et al., 1998). Desta forma, o presente trabalho teve como objetivo a obtenção de mudas de macieira a partir de plantas microenxertadas, sob a aplicação de reguladores de crescimento em diferentes combinações de microenxertos.

\section{MATERIAL E MÉTODOS}

O trabalho foi conduzido no Laboratório de Morfogênese e Bioquímica Vegetal do Departamento de Fitotecnia da Universidade Federal de Santa Catarina, nos anos de 2000 e 2001.

\section{Material vegetal}

A cultivar Gala (Malus domestica Borhk) e os porta-enxertos de macieira M9 (Malus pumila Mill) e Marubakaido (Malus prunifolia) foram introduzidos in vitro, através do isolamento dos meristemas apicais e axilares. As gemas que serviram de fonte de explantes, foram retiradas de plantas-matrizes, mantidas em casa de vegetação. A assepsia foi realizada através da imersão das gemas apicais em etanol a $70 \%$ (v:v) por 1 minuto e hipoclorito de sódio a $1 \%$ por 20 minutos, seguido de três lavagens em água destilada e autoclavada em câmara de fluxo laminar. As gemas apicais foram mantidas em solução de ácido ascórbico a $1,5 \%$ durante 15 minutos e, posteriormente, foram obtidos os ápices meristemáticos, os quais foram inoculados em tubos de ensaio, contendo $10 \mathrm{~mL}$ de meio MS (Murashige \& Skoog, 1962), acrescido de sacarose (30 g.L - $\left.^{-1}\right)$, ágar $(6$ g.L-1) (Sigma Chemical Company, EUA) e suplementado com 6 - benzilamino purina (BAP) $(1,1$ $\mu \mathrm{M})$ para os porta-enxertos e com BAP $(2,2 \mu \mathrm{M})$ para cultivar Gala. Todas as culturas foram mantidas no escuro por 3 dias e, após este período, foram transferidas para sala de crescimento sob regime de 16 horas de fotoperíodo, em temperatura de $24 \pm 2{ }^{\circ} \mathrm{C}$, sob radiação luminosa de $40 \mu \mathrm{mol} . \mathrm{m}^{-2} \cdot \mathrm{s}^{-1}$, fornecida por lâmpadas brancas fluorescentes. Subcultivos dos genótipos foram feitos a cada quatro semanas, por três vezes, para a proliferação de brotos.

\footnotetext{
'(Trabalho 004/2004). Recebido: 22/04/2004. Aceito para publicação: 21/01/2005.

${ }^{2}$ M.Sc. Recursos Genéticos Vegetais, CCA, UFSC, Florianópolis, SC.

${ }_{3}^{3}$ Bolsista PIBIC/BIP/CNPq/UFSC, CCA/UFSC, Florianópolis, SC. E-mail: monitaf@yahoo.com

${ }^{4}$ Dra.Pesq. PRODOC/CAPES, CCA, UFSC, Florianópolis, SC. E- mail: acmdantas@ cca.ufsc.br

${ }^{5}$ Pesquisador da Epagri - E.E. São Joaquim Caixa Postal 81. Cep 88600-000. São Joaquim, SC. E-mail: pereira@ epagri.rct-sc.br

${ }^{6}$ Dr. Prof. Depto. Fitotecnia, CCA, UFSC. Caixa postal 476 CEP:88040 -970, Florianópolis, SC. E-mail: pedrotti@ @ca.ufsc.br
} 


\section{Preparo dos microenxertos}

Utilizaram-se como explante brotações obtidas da multiplicação in vitro dos porta-enxertos M9 e Marubakaido e da cultivar Gala. Das brotações dos porta-enxertos, foi retirada a parte apical, padronizandose a altura em $5 \mathrm{~cm}$. Para a cultivar Gala, foram preparados microgarfos com apenas uma gema lateral, de aproximadamente $1 \mathrm{~cm}$. As bases dos microgarfos da copa foram imersas em solução de 1:1 ácido ascórbico (150 mg.L-1) e ácido cítrico (150 mg.L-1) para evitar oxidações.

Através de um corte em fenda simples (Hartmann et al., 1990; Abreu et al., 2003), realizado nas plântulas dos porta-enxertos, e um corte em bisel no microgarfo da cultivar copa, foi realizada a microenxertia com auxílio de pinças. Foram feitas as combinações da cultivar Gala microenxertada sobre M9 (Gala/M9) e Gala microenxertada sobre Marubakaido (Gala/Marubakaido).

\section{Efeito do BAP e AIB}

Os microenxertos foram inoculados em sais e vitaminas MS, contendo sacarose (30 g.L $\left.\mathrm{L}^{-1}\right)$, ágar (6 g.L $\left.\mathrm{L}^{-1}\right)$, com os seguintes tratamentos: $\mathrm{MS}_{0}$ : MS com BAP $(2,2 \mu \mathrm{M}) ; \mathrm{MS}_{1}$ : MS com metade da concentração de sais (MS/2), suplementado com AIB $(2,2 \mu \mathrm{M})$ e $\mathrm{MS}_{2}$ : $\mathrm{MS} / 2$, suplementado com $\mathrm{AIB}(2,2 \mu \mathrm{M})$, com pré-tratamento adicional de AIB $(4 \mu \mathrm{M})$ no ponto de enxertia, para ambos os porta-enxertos. $\mathrm{O} \mathrm{pH}$ foi ajustado para 5,8 antes da adição do ágar. As condições de cultivo deste experimento foram idênticas às descritas anteriormente.

Após 30 dias de cultivo in vitro, foram realizadas as seguintes avaliações: percentagem de microenxertos viáveis, altura da copa e o número de folhas dos microenxertos. $\mathrm{O}$ delineamento experimental utilizado foi o completamente casualizado, com sete repetições, contendo cinco plantas por repetição. Os dados foram submetidos à Análise da Variância (ANOVA) com teste de separação de médias SNK ao nível de $5 \%$ de probabilidade (Steel \& Torrie, 1980).

\section{Aclimatização dos microenxertos}

Após 30 dias de cultivo, os microenxertos foram enraizados in vitro em meio MS/2, contendo sacarose (30 g.L-1), ágar (6 g.L-1), suplementado com AIB $(1,1 \mu \mathrm{M})$ para Gala/Marubakaido e AIB $(4,4 \mu \mathrm{M})$ para Gala/M9. Após a indução de raízes, aproximadamente 15 dias, as plantas foram transferidas para bandejas de isopor alveoladas com substrato comercial Turfafértil ${ }^{\circledR}$, colocadas em caixas plásticas com tampa de vidro para manter a umidade relativa em saturação. Estas foram mantidas em Fitotron, à temperatura de $28 \pm 1{ }^{\circ} \mathrm{C}$, fotoperíodo de 16 horas, $80 \%$ de umidade relativa e radiação de $450 \mu$ mol.m ${ }^{-2} . \mathrm{s}^{-1}$, por mais 30 dias. Após este período, foram realizadas avaliações da percentagem de sobrevivência, altura da copa e número de folhas dos microenxertos.

\section{RESULTADOS E DISCUSSÃO}

\section{Efeito do BAP e AIB}

A primeira evidência de proliferação celular observada nos microenxertos ficou evidente com o restabelecimento do crescimento da copa, aos 12 dias após a realização dos microenxertos, com a formação de calos na interface entre copa e porta-enxerto (Figura 1a e 1b). Este fato foi mais expressivo em Gala/Marubakaido (Figura 1b).

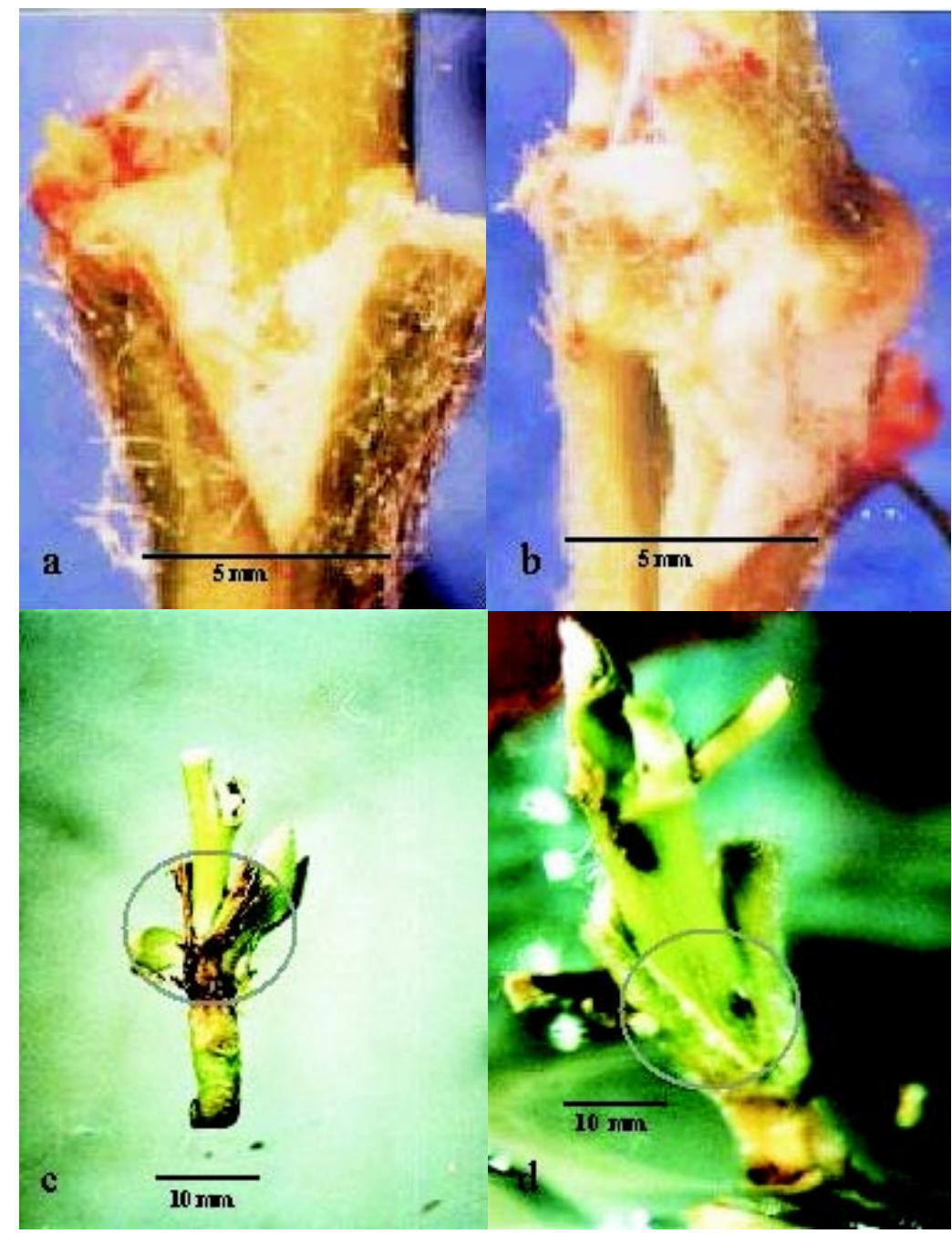

FIGURA 1 - Aspectos morfológicos dos porta-enxertos de macieira. a) Microenxerto de Gala sobre M9 (12 dias de cultivo in vitro); b) Formação de calos no microenxerto de Gala sobre M9 (12 dias de cultivo in vitro); c) Oxidação no ponto de enxertia (30 dias de cultivo in vitro); d) Deslocamento no ponto de enxertia (3 dias de cultivo in vitro). 
TABELA 1 - Percentagem de viabilidade, comprimento dos porta-enxertos, altura e número de folhas de microenxertos de macieira obtidos nos diferentes microenxertos. CCA/UFSC, 2000-2001.

\begin{tabular}{lcc}
\hline $\begin{array}{c}\text { Concentração de } \\
\text { fitorreguladores }\end{array}$ & Viabilidade (\%) & Altura da copa (cm) \\
\hline & & Gala enxertada ao M9 \\
\hline $2,2 \mu \mathrm{M}$ de BAP & $79,6 \mathrm{a}$ & $1,8 \mathrm{a}$ \\
$2,2 \mu \mathrm{M}$ de AIB & $93,2 \mathrm{a}$ & $1,46 \mathrm{ab}$ \\
$4 \mu \mathrm{M}$ de AIB * & $86,4 \mathrm{a}$ & $1,52 \mathrm{ab}$ \\
\hline & & Gala enxertada ao Marubakaido \\
\hline $2,2 \mu \mathrm{M}$ de BAP & $73,0 \mathrm{a}$ & $1,52 \mathrm{ab}$ \\
$2,2 \mu \mathrm{M}$ de AIB & $79,8 \mathrm{a}$ & $1,16 \mathrm{~b}$ \\
$4 \mu \mathrm{M}$ de AIB * & $86,4 \mathrm{a}$ & $1,68 \mathrm{a}$ \\
\hline Médias seguidas de mesma letra não diferem significativamente pelo teste de separação de médias SNK, ao nível de 5\% *Aplicação no ponto de enxertia.
\end{tabular}

TABELA 2 - Percentagem de sobrevivência, altura e número de folhas obtidas em diferentes microenxertos de macieira após aclimatização. CCA/ UFSC, 2000-2001.

\begin{tabular}{lccc}
\multicolumn{1}{c}{ Microenxertos } & Sobrevivência (\%) & Altura da copa (cm) & $\mathbf{N}^{\mathbf{0}}$ Folhas \\
\hline Gala/M9 & $88,5 \mathrm{a}$ & $6,7 \mathrm{a}$ & $8,4 \mathrm{a}$ \\
Gala/Marubakaido & $92,5 \mathrm{a}$ & $7,2 \mathrm{a}$ & $8,9 \mathrm{a}$ \\
\hline
\end{tabular}

Médias seguidas de mesma letra não diferem significativamente, pelo teste de separação de médias SNK, ao nível de 5\%.

A percentagem de viabilidade dos microenxertos, referente à conexão vascular dos tecidos, variou de 73 a $93,2 \%$ entre os tratamentos (Tabela 1). A percentagem de viabilidade observada em Gala/M9 (93,2 $\%$ ), em meio MS/2 suplementado de 2,2 $\mu \mathrm{M}$ de AIB, seguido do meio MS/2 com pré-tratamento de AIB $(4 \mu \mathrm{M})$, em ambas as combinações $(86,4 \%)$, apresentou valores elevados (Tabela 1$)$; contudo, estes valores não foram significativamente diferentes pelo teste $\operatorname{SNK}(p=0,05)$.

Resultados obtidos demonstraram que o tratamento com reguladores de crescimento no ponto de enxertia aumentou significativamente a viabilidade dos enxertos (Mosella-Chancel et al., 1980b). Alskief e Villemur (1977) e Martinez et al. (1979), inserindo blocos de ágar contendo solução com 5,7 $\mu \mathrm{M}$ de ácido indolacético (AIA) entre o ápice e porta-enxertos de Prunus sp., verificaram aumento na viabilidade dos enxertos. A mesma resposta foi obtida por Jonard (1986), que recomendou o uso de ácido naftalenoacético (ANA) $(2,7 \mu \mathrm{M})$ para aumentar a percentagem de viabilidade dos enxertos em Prunus sp. Entretanto, em plantas cítricas, Starrantino \& Caruso (1988) observaram que tratamentos com BAP $(2,2 \mu \mathrm{M})$ aumentaram a viabilidade dos mesmos de 40 para $90 \%$.

Para a altura da copa e o número de folhas dos microenxertos, não foram observadas diferenças significativas, em Gala/M9 com 2,2 $\mu \mathrm{M}$ de BAP, mesmo apresentando altura média de $1,8 \mathrm{~cm}$ e número de folhas na copa igual a 1,32 (Tabela 1). Entretanto, para Gala/Marubakaido, a aplicação de $4 \mu \mathrm{M}$ de AIB e 2,2 $\mu \mathrm{M}$ de BAP foram os melhores tratamentos para o número de folhas dos microenxertos, com 1,20 e 1,34, respectivamente, não diferindo estatisticamente entre eles.

O tratamento com AIB no ponto de enxertia apresentou $20 \%$ a mais de sobrevivência sobre o tratamento com BAP, contudo não houve diferença significativa segundo o teste SNK. A conexão dos tecidos no ponto de enxertia resulta em maior sobrevivência dos enxertos (Lessa, 1998). Foi observada em algumas regiões, a proliferação de calos, os quais evoluíram para uma necrose, como união física final entre a copa e o porta-enxerto, o qual causou aumento de volume no local de união dos tecidos (Figura 1b). A aplicação de reguladores de crescimento no ponto de enxertia aumenta o potencial regenerativo dos tecidos, especialmente no tecido do câmbio, pelo alongamento e formação de novas camadas celulares, assegurando o estabelecimento da continuidade da vascularização entre o porta-enxerto e a copa (Jeffree \& Yeoman, 1983).

A inviabilidade constatada se deve a alguns fatores, como o deslocamento da copa sobre o porta-enxerto, gerando um desemparelhamento nos tecidos vasculares entre a copa e o porta-enxerto, causando oxidação no sítio da união (Figura 1c). Adicionalmente, o desenvolvimento de novas brotações foi observado nos porta-enxertos, próximo da área de união, o que também contribuiu para o deslocamento da copa (Figura 1d).

\section{Aclimatização dos microenxertos}

$\mathrm{Na}$ aclimatização, foram não observadas diferenças significativas entre os tratamentos em todas as variáveis analisadas. A sobrevivência dos microenxertos foi de $92,5 \%$ para a combinação Gala/ Marubakaido e 88,5\% para a Gala/M9 (Tabela 2). Para a altura e número de folhas, Gala/Marubakaido também apresentou valores superiores aos encontrados em Gala/M9, apesar de não ser estatisticamente significativo.

Estes resultados mostram que o período crítico para a garantia da viabilidade dos microenxertos é o momento da realização da enxertia in vitro. Pois, após ter sido corretamente realizada a técnica (momento de encaixe), os microenxertos se desenvolvem normalmente e não ocorrem dificuldades na transferência destes para casa de vegetação (Zanol et al., 1997). Após a aclimatização, a percentagem de sobrevivência nos microenxertos foi superior a $80 \%$ para ambas as combinações testadas.

\section{CONCLUSÕES}

1. Os resultados mostraram a possibilidade de produzir mudas de macieira microenxertadas para os porta-enxertos e a cultivar copa estudada.

2. Para Gala/M9, não houve diferença significativa entre os tratamentos, porém, para Gala/Marubakaido, os tratamentos mais eficientes para o número de folhas foram $2,2 \mu \mathrm{M}$ de AIB em meio MS e 4 $\mu \mathrm{M}$ de AIB no ponto de enxertia.

3. O transplante das plantas microenxertadas para casa de vegetação permitiu o desenvolvimento da copa, resultando na alta sobrevivência em todos os tratamentos.

\section{REFERÊNCIAS}

ABREU, M.F.; NUNES, J.C.O.; SANTOS, M.; PEDROTTI, E.L. Estudos histológicos preliminares da microenxertia de plantas micropropagadas de macieira. Revista Brasileira de Fruticultura, Jaboticabal, v.25, n.1, p.195-196, 2003.

ALSKIEF, J.; VILLEMUR, P. Greffage in vitro d'apex sur des plantules decapitées de pommier (Malus pumila Mill.) Comptes Rendus de l'Academie des Sciences Serie D, Paris, v.287, p. 1115-1118, 1977.

ALONI, R. Differentiation of vascular tissues. Annual Review of Plant Physiology, Palo Alto, v.38, p.179-204, 1987.

BONETTI, J.I.S.; PEREIRA, A.J.; BRIGHENTI, E.; KATSURAYAMA, Y.; TSUCHIYA, S. Situação atual e perspectiva de obtenção de cultivares e porta-enxertos de macieira ressitentes às doenças, para a Região Subtropical. In: SEMINÁRIO SOBRE FRUTICULTURA DE CLIMA TEMPERADO, 1., 2001, Florianópolis, SC. Anais... Florianópolis: EPAGRI, 2001.p. 39-52. 
ESTRADA-LUNA, A.A.; LÓPEZ-PERALTA, C.; CÁRDENASSORIANO, E. In vitro micrografting and the histology of graft union formation of selected species of prickly pear cactus (Opuntia spp.). Scientia Horticulturae, Amsterdan, v.92, p. 317-327, 2002.

HARBAGE, J. F. ; STIMART, D. P.; AUER, C. pH affects 1h-indole-3butyric acid uptake but not metabolism during the initiation phase of adventitious root induction in apple microcuttings. Journal of the American Society for Horticultural Science, Alexandria, v.123, n.1, p. 6-10, 1998.

HARTMANN, H.T.; KESTER, D.E.; DAVIES JR., F.T.D. Plant propagation, principles and practices. Englewood Cliffs: New Jersey, 1990.647p.

JEFFREE, C.E.; YEOMAN, M.M. Development of intercellular connections between opposing cells in graft unions. New Phytologist, New York, v.93, n.4, p.491-509, 1983.

JONARD, R. Micrografting and its applications to tree improvement. Biotechnology in Agriculture and Forest, Berlin, v.1, p.741-743, 1986.

LAMBARDI, M.; BENELLI, C.; FABBRI, A. In vitro axillary shoot proliferation of apple rootstocks under different ethylene conditions. In Vitro Cellular \& Developmental Biology-Plant, Wallingford, v.33, n.1,p.70-74, 1997.

LESSA, A. O. Utilização de microenxertia para a obtenção de plantas de Malus domestica Borkh livres do vírus da mancha clorótica das folhas da macieira (ACLSV). 1998. 78f. Tese (Doutorado em Fitotecnia) - Universidade Federal do Rio Grande do Sul, Porto Alegre, 1998.

MARTINEZ, J.; MUGARD, J.; JONARD, R. Sur les differentes combinaisons de greffages des apex reslisés in vitro entre Pecher (Prunus persica Batsch), Abricotier (Prunus armeniaca L.) et Myrobalan (Prunus cerasifera Ehrh.). Comptes Rendus de l'Academie des Sciences Serie D, Paris, v.288, p.257-262, 1979.

MURASHIGE, T.; SKOOG, F. A revised medium for rapid growth and bioassays with tobacco tissue cultures. Physiologia Plantarum, Copenhagen, v.15, p.473-497, 1962.

MURASHIGE, T.; BITTERS, W.P.; RANGAN, T.S.; NAUER, E.M.; ROISTACHER, C.N.; HOLLIDAY, P.B. A technique of shoot apex grafting and its utilization towards recovering virus-free Citrus clones. HortScience, Alexandria, v.7, p.118-119, 1972.

MOSELLA-CHANCEL, L.; SIGNORET, P.A.; JONARD, R. Sur la mise au point de techniques de microgreffage d'apex en vue de l'elimination de deux types de particules virales chez le Pecher (Prunus persica Batsch). Comptes Rendus de l'Academie des Sciences Serie D,
Paris, v.290, p.287-290, 1980a.

MOSELLA-CHANCEL, L.; MACHEIX, J.J.; JONARD, R. Les conditions du microbouturage in vitro du Pecher (Prunus persica Batsch), influences combinées des substances de croissance et de divers composés phenoliques. Physiologia Plantarum, Copenhagen, v.18, p. 597-608, 1980b.

NAVARRO, L. Application os shoot-tip grafting in vitro to woody species. Acta Horticulturae, Wageningen, v.227,p.43-55, 1988.

NAVARRO, L.; ROISTACHER, C.N.; MURASHIGE, T. Improvement of shoot-tip grafting in vitro for virus-free Citrus. Journal of the American Society for Horticultural Science, Alexandria, v.100, p.471-479, 1975.

PRAKASH, O.; SOOD, A.; SHARMA, M.; AHUJA, P.S. Grafting micropropagated tea [Camellia sinensis (L.) O. Kuntze] shoots on tea seedlings - a new approach to tea propagation. Plant Cell Reports, Berlin, v.18, p.883-888, 1999.

RICHARDSON, F.V.M.; MACANTSOIR, S.; HARVEY, B.M.R. A study of the graft union in in vitro micrografted apple. Plant Growth Regulation, Dordrecht, v.20, p.17-23, 1996.

STARRANTINO, A.; CARUSO, A. The shoot-tip grafting technique applied in citriculture. Acta Horticulturae, Wageningen, v.227, p.101$103,1988$.

STEEL, R.G.D.; TORRIE, J.H. Principles and procedures of statistics-A biometrical approach. 2.ed. New York: Macgraw-Hill, 1980.p. 633

TANNÈ, E.; SHLAMOVITZ, N.; SPIEGEL-ROY, P. Rapidly diagnosing grapevine corky-bark by in vitro micrografting. HortScience, Alexandria, v. 28, n. 6, p.667-668, 1993.

ZANOL, G.C.; FORTES, G. R. de L.; SILVA, J. B. da; CAMPOS, A. D.; CENTELLAS, A.Q.; MÜLLER, N. T.; GOTTINARI, R. A. Escuro e ácido indolbutírico no enraizamento in vitro e atividade da peroxidase de porta-enxertos de macieira, Cv. Marubakaido (Malus prunifolia). Revista Brasileira de Agrociência, Pelotas, v.3, n.1, p.23-30, 1997.

ZECCA, A. G. D. Micro-enxertia, enxertia de calo e enxertia de microestaca sobre calo, "in vitro", como método de determinação de incompatibilidade de pereira (Pyrus spp.) sobre marmeleiro (Cydonia oblonga). 1995. 110f. Dissertação (Mestrado em Fruticultura de Clima Temperado, Programa de Pós-Graduação em Agronomia) - Universidade Federal de Pelotas, Pelotas, 1995.

ZHU, L.H.; WELANDER, M.; HELLGREN, O. Growth rates and biomass production of micropropagated apple plants of M26 and Gravenstein on their own roots and in different micrografted combinations under non-limiting and limiting nutrient conditions. Journal of Experimental Botany, Oxford, v.50, n. 336, p.1189-1198, 1999. 